\title{
Chinese Patent—A Tentative Explanation of Various Strategies of Patenting
}

\author{
Dou Henri \\ Atelis, Strategic Intelligence Workroom, France Business School (FBS), Tours, France \\ Dou Jean-Marie Jr \\ Chamber of Commerce and Industry CCIMP, Marseille, France
}

\begin{abstract}
The recent increase in patent granted in China prompts for an analysis of the various strategies which are certainly developed by Chinese applicants in that field. An analysis (APA Automatic Patent Analysis) has been done in several fields which have different impacts on the Chinese economy. We chose four different subjects: solar panels; photovoltaic panels; fireworks; and honeysuckle. These areas go from deep international concern to only Chinese interest. We analyzed in the different ratios between Chinese priority patents, Chinese patents extended to other countries, Patent extended from other countries to China and Chinese utility models. The results show clearly that various directions are followed depending on the economic importance of the field and also the pressure of the competition inside and outside China. In this context the strategic dependence (number of patents extended to China by other countries) was examined for each of the fields. We also show that in the domain where the man power is important such as fireworks the number of utility models is important. This suggests that utility models are used to spread in that field minor innovations. In the fields such as honeysuckle many applicants are the same that the inventors and the involvement of universities larger than in other fields. These two fields more or less centered on Chinese domestic aspects only a few patents (not for Honeysuckle) are extended to other countries. The impact of foreign patents in these two fields is quasi nil. In other domains such as photovoltaic panel the triadic patents (extension to US JP EP) are examined its show that if some Chinese patents are extended to other countries there are also an important numbers of foreign patents extended to China. This also suggests that in these most critical subjects, China develops a sort of technological protection barrier from domestic patents. This underlines a strategy on attack and defense in that field.
\end{abstract}

Keywords: automatic patent analysis, fireworks, honeysuckle, solar panel, China, strategic dependence

\section{Material and Method}

The increasing number of patents granted in China prompts us to make an analysis of the patents granted in various subjects to see if there is a possible way out of this analysis to underline a Chinese management policy in

Dou Henri, University Professor, Atelis, Strategic Intelligence Workroom, France Business School (FBS).

Dou Jean-Marie Jr, Ph.D., Project Manager, Chamber of Commerce and Industry CCIMP.

Correspondence concerning this article should be addressed to Dou Henri, Atelis, France Business School, 1 rue Léo Delibes, 37205, Tours Cedex France. E-mail: douhenri@yahoo.fr. 
Intellectual Property Management (IPM). The trend in patents granted in the world and in China is presented in Table 1.

Table 1

Number of patents filled in the world (Tribune, 2010)

\begin{tabular}{|c|c|c|c|c|c|}
\hline \multirow[b]{2}{*}{ Office } & \multicolumn{5}{|c|}{ Application year } \\
\hline & 2008 & 2009 & 2010 & Share of total (\%): 2010 & Growth (\%): 2009-2010 \\
\hline Total & $1,915,000$ & $1,846,000$ & $1,979,000$ & 100.0 & 7.2 \\
\hline United States of America & 456,321 & 456,106 & 490,226 & 24.8 & 24.3 \\
\hline China & 289,838 & 314,604 & 391,177 & 19.8 & 7.5 \\
\hline Japan & 391,002 & 348,596 & 344,598 & 17.4 & -1.1 \\
\hline Republic of Korea & 170,632 & 163,523 & 170,101 & 8.6 & 4.0 \\
\hline European Patent Office & 146,150 & 134,580 & 150,961 & 7.6 & 12.2 \\
\hline Germany & 62,417 & 59,583 & 59,245 & 3.0 & -0.6 \\
\hline Russian Federation & 41,849 & 38,564 & 42,500 & 2.1 & 10.2 \\
\hline Canada & 42,089 & 37,477 & 35,449 & 1.8 & -5.4 \\
\hline India* & 36,812 & 34,287 & - & 1.9 & -6.9 \\
\hline Australia & 26,346 & 23,681 & 24,887 & 1.3 & 5.1 \\
\hline Brazil & 22,917 & 21,944 & 22,686 & 1.1 & 3.4 \\
\hline United Kingdom & 23,379 & 22,465 & 21,929 & 1.1 & -2.4 \\
\hline France & 16,419 & 15,693 & 16,580 & 0.8 & 5.7 \\
\hline Mexico & 16,581 & 14,281 & 14,576 & 0.7 & 2.1 \\
\hline China, HongKong SAR & 13,662 & 11,857 & 11,702 & 0.6 & -1.3 \\
\hline Others & 125,586 & 148,759 & 182,383 & 9.2 & 22.6 \\
\hline
\end{tabular}

Notes. Application numbers are a sum of direct filings and PCT national phase entries received by offices. * Share of total applications is based on 2009 total and growth is based on 2008-2009 figures; “-” not available.

To perform the various analysis we used the Matheo-Patent software (Matheo Software, 2013) facilities to query the patent database (World Patent Database from the EPO (European Patent Office), OPS VI). This database gives an access to all patents including Chinese patents. The Matheo-Patent resident software allows to query the database and to update the results if necessary. From the local database thus created various bibliometric analysis can be performed (Dou et al., 2005). Mostly they will answer to the questions: who is doing what, with whom, when, how? We took four subjects: the solar panels; the photovoltaic panels; the fireworks; and the honeysuckle. These four subjects give rise to four local databases which were analyzed to show: the number of patents with a Chinese priority versus the global number of patents and versus to foreign patents. The same was done for the extended Chinese patents (there is a delay of 12 months which allows you to extend a patent to another country). We also analyze the number of utility models versus the global number of Chinese patents. The utility models are what is called petty patents, that is to say a system which give a lighter protection that the genuine patents (protection span 10 years in China instead of 20, lower cost, and easy examination) (WIPO 2012). A patent with a Chinese priority means that the first patent granted to protect this invention as been granted in China $(\mathrm{PR}=\mathrm{CN})$. The patent numbers dealing with China concern all Chinese priority patents plus patents from other countries extended to China $(\mathrm{PN}=\mathrm{CN})$. 


\section{Results}

We choose various subjects which covers different situations in China, some with a deep Chinese concern and one with a more international impact. From the study of the different patent, priority, and ratio of PN versus PR patent, we will try to see if a strategy in patent deposit can be detected.

\section{Solar Panels}

The research was done with a general query solar and panel in the title of the patents, from 2009 to December 2011. The search for title words allows to select the most important patents. The results are summarized in Table 2.

Table 2

Analysis of the China Solar Panel Patents

\begin{tabular}{lcc}
\hline Type of patents & Number of patents & Number of families \\
\hline Patent number CN & 202 & 202 \\
Patent priority CN & 180 & 179 \\
CN patent not extended & 166 & 166 \\
Utility models CN & 69 & 69 \\
Utility models (total patents) & 71 & 71 \\
Foreign patents extended to CN & 30 & 30 \\
CN patent extended & 13 & 13 \\
Total number patents & 1,017 & \\
\hline
\end{tabular}

China concentrates about $20 \%$ of all the patents or utility models granted in that field. Utility models are widely used in China. The two other utility models used are from United States. The utility models are not extended to other countries. Most of the Chinese patents are not extended, which means that all the information described in this patents or utility models can be used freely by other countries. The number of Chinese patents extended to other countries (or as W0 patents) is 13, about 7.20\%. The number of patents from other countries extended to China is 30 , about $3.58 \%$.

\section{Fireworks}

This is an important domain for China since most of the fireworks are made in China. But, the use of the fireworks made in China can give rise to patents (electronic management, etc.). For this reason it could be a challenge in global Chinese patents for this domain. The search was done with firework in the title or abstract. The total number of patents was 1,055 from 2005 to December 2011. The results are summarized in Table 3.

China concentrate about $78.29 \%$ of patents or utility models of that field. The number of utility models is very large: 560 which is about $67.79 \%$ of the total of the Chinese patents or utility models. These utility models are not extended to foreign countries. Other countries do not used utility models only one is coming from Ukraine. The percent of Chinese patents extended to other countries is $0.96 \%$. The percent of foreign patents extended to China is $2.22 \%$.

\section{Honeysuckle}

This field has been chosen because it concerns directly China. Honeysuckle derivatives are used in beverages and China medicine. The search was done using the term honeysuckle in title and limited from 2000 to December 2011. The total number of patent is 284. The results are summarized in Table 4. 
Table 3

Analysis of the Chinese Fireworks Patents

\begin{tabular}{lcc}
\hline Type of patents & Number of patents & Number of families \\
\hline Patent number CN & 831 & 821 \\
Patent priority CN & 826 & 826 \\
CN patent not extended & 818 & 818 \\
Utility models CN & 560 & 560 \\
Utility models (total patents) & 561 & 561 \\
Foreign patents extended CN & 5 & 5 \\
CN patent extended & 8 & 8 \\
Total number patents & 1,055 & \\
\hline
\end{tabular}

Table 4

Analysis of the Chinese Honeysuckle Patents

\begin{tabular}{lcc}
\hline Type of patents & Number of patents & Number of families \\
\hline Patent number CN & 217 & 217 \\
Patent priority CN & 217 & 217 \\
CN patent not extended & 217 & 217 \\
Utility models CN & 10 & 10 \\
Utility models (total patents) & 10 & 10 \\
Foreign patents extended CN & 0 & 0 \\
CN patent extended & 0 & 0 \\
Total number patents & 284 & 284 \\
\hline
\end{tabular}

Chinese patents represent about $76.40 \%$ of the field. The utility models represent $4.60 \%$ of the total of the Chinese patents and utility models. There are no Chinese patents extended to foreign countries neither foreign patent extended to China.

\section{Solar Photovoltaic Panels}

This subjects was choose to show the difference in strategy when a subject is directly link to the Chinese economy and export. The search was done by using the International Patent Classification (IPC) (IPC, 2013). We used the IPC:

H01L 31/042 were H01L = Semiconductor Devices; Electric Solid State Devices and 31/042 including a panel or array of photoelectric cells, e.g., solar cells.

The search was limited to the year 2012 for the purpose of the example. The total patents retrieves is 907 . The results are summarized in Table 5 .

The patents with Chinese priority represent about $4.11 \%$ of the total patents. There is no utility model. The foreign patents extended to China increases about $7.70 \%$ of the amount of foreign patents. The ratio of extended Chinese patents being $7.05 \%$.

The number of patents extended by other countries to China indicates a certain degree of dependence of China versus these patents: this is the concept of strategic dependence which is not the subject of this paper, but which has been detailed recently (Dou et al., 2011). 
Table 5

Analysis of the Chinese Solar Photovoltaic Panels

\begin{tabular}{lll}
\hline Type of patents & Number of patents & Number of families \\
\hline Patent number CN & 188 & 188 \\
Patent priority CN & 128 & 128 \\
CN patent not extended & 119 & 119 \\
Utility models CN & 0 & \\
Utility models (total patents) & 0 & 69 \\
Foreign patents extended CN & 69 & 9 \\
CN patent extended & 9 & \\
Total number patents & 907 & \\
\hline
\end{tabular}

\section{Tentative Explanation}

One important point must be recalled before any explanation tentative. This is the concept of strategic dependence (Dou, 2012). This means that if a foreign country extends some of its patents in another country, this later will be technological dependent of the invention described in the foreign extended patents. To avoid a too large dependence, many countries such as China analyses the sectors of dependence (patents with the priority in the country, versus extended foreign patents). Then, to avoid such a dependence the strategy is to patent (only with the Chinese priority) many inventions related to these sectors. This will build up a sort of barrier, and if you want to extend a patent or to import in China various products or services, they will face the local Chinese patents and then you will not be sure to win an action in front of a Chinese court.

From the above data:

(1) In domains where the concurrence is domestic as in the case of fireworks or honeysuckle two main strategies may be seen:

- Fireworks which are man power consuming activity with various know-how, many people used the utility models to protect their know-how, or better to try to sell it. It can be seen from the large number of inventors which appear also as applicants-They will share the price of cost of the patent, also the royalties if any. Universities are also active as applicant in that field;

- Honeysuckle, this is a large market with a lot of domestic competition. This can be seen through a lower numbers of individual applicants, and almost no use of utility models. Universities are also active in that field. It is also noticeable that in spite of some foreign patents none are extended to China.

(2) In domains which are more technical, such as the solar panels (in general) and the photovoltaic panels the situation remains in between. The global amount of patents in the field increases and the amount of Chinese patents (priority Chinese) seems to decrease according to the level of the technology. The most sophisticated is the lower numbers of Chinese patents, for instance, fireworks 78\%, honeysuckle $76 \%$, solar panels (in general) 20.9\%, photovoltaic panels about 5\%. In the same time, the amount of foreign patents extended to China increases with the level of the technology involves. In the same time, the percent of Chinese patent extended to other countries increase when this is a technical domain more or less related to export: about 7\% for both panels applications, $1 \%$ for fireworks very manpower consuming and low technology without no competitor in the development of the cracks and fireworks themselves, and $0 \%$ for the honeysuckle where there is no international competition at all. But, the large number of Chine priority patents as well as the large number of utility models in 
certain fields, suggest a strong internal competition since they are not extended to other countries.

\section{Applicant Profiles}

One good indicator also of the activity in Chinese patenting is the analysis of the applicant field. The amount of individuals (as applicants) versus the companies or universities (as applicants), is interesting. Of course it can be used only if the assumption that in companies this is the companies names which appear as applicants and not only the inventor's names is true. For instance, for the fireworks the percent of individuals as applicants is $29 \%$ and for the honeysuckle is $41 \%$. For the solar panel (general) the ratio of individual applicants versus universities or firms is $26 \%$. Then, when the subject is more "industrial”, the number of individuals as applicants decreases. In the case of the honeysuckle, many Chinese individuals take some patents because this field is almost totally Chinese with various applications in beverages, teas, Chinese medicines, based on not very complicated technologies. Another remark about the applicant's profile is that we did not find co-applicants (University-University or Industry-University or Industry-Industry). This suggests that the state of a true triple helix or Public or Private Partnership (PPP) is not yet commonly reach (Leydesdorff \& Etzkowitz, 1998).

\section{The Triadic Patents}

The term "triadic patents" has been developed by the OECD (OECD, 2005) for a patent which is extended in USA, Europe (EP), and Japan. The triadic patents were referenced as good and important patents. Today, the best is to look for WO patents and the designated states which most of the time included USA, Europe, and Japan. Then if we take a domain such as the solar photovoltaic panels the result is as follows:

The number of WO families is 167 out of this number seven are Chinese and there are also two Chinese patents extended to USA.

The analysis of the foreign families with one Chinese extension is as follows:

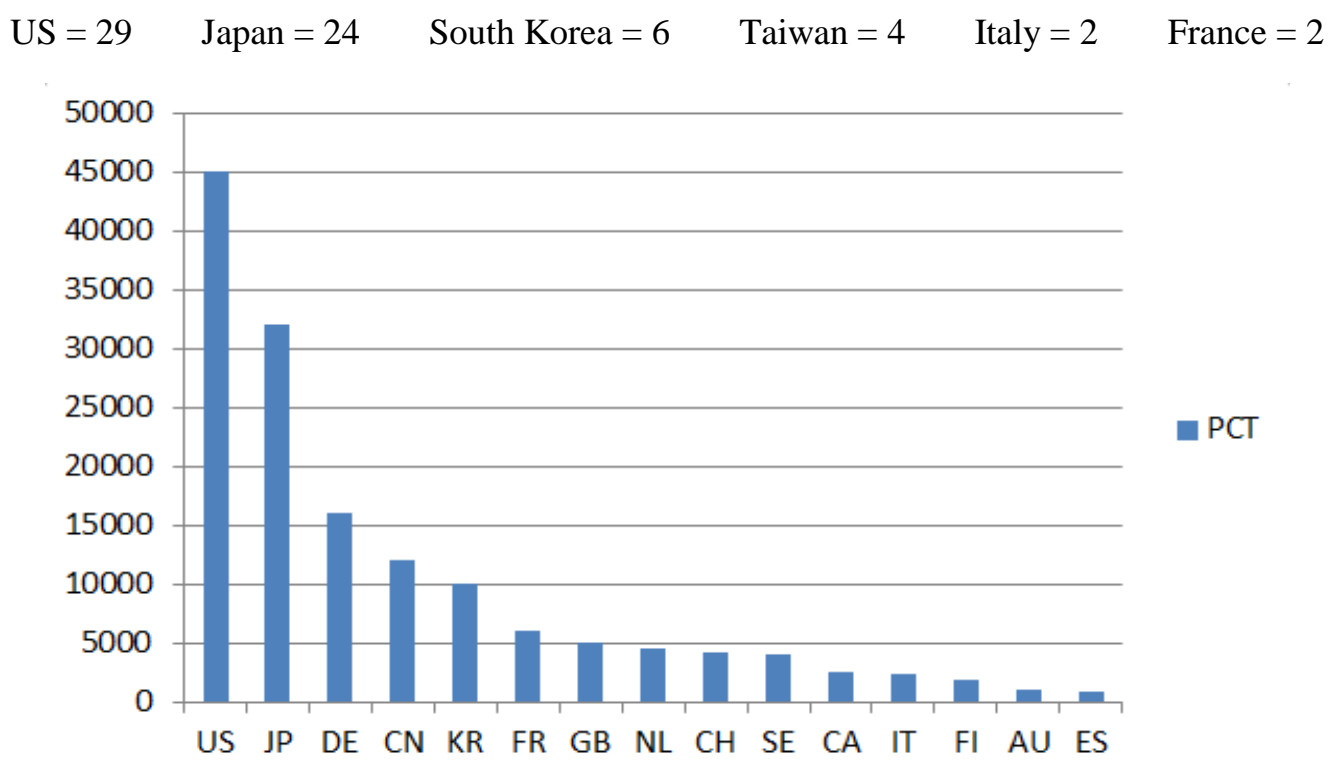

Figure 1. China contribution to international patent applications received in 2010.

Then according to the vision of the problem one may said that only nine Chinese patents are important, or that most of the Chinese patents are useful to protect the Chinese interests in China as well as to be related to 
domestic Chinese competition. Figure 1 indicates the amount of Patent Cooperative Treaty (PCT) from various countries in 2010. China becomes the fourth contributor (PEN, 2012).

\section{Conclusions}

It is clear that China will become the most important country in the field of intellectual property. But if we look to the strategy of the management of the intellectual property three aspects must be deducted from this study:

\section{The Chinese Patents Extended}

Chinese patents extended to the world are mainly WO patents, some of them (but rarely extended only to US) are not very large compared with the total number of patents with a Chinese priority but not extended.

\section{The Chinese Patents Which Are not Extended}

They are the patent with only a Chinese priority (Priority China), these patents are reflecting of two strategies:

One is to avoid the strategic dependence. This is the defense of the geographical territory of China. The second one reflects the domestic competition and the use of patents as a vector of possible gains.

\section{The Utility Models}

The utility models are not really patents. In this case they are related to a domestic competition, but more certainly the idea to get some money out of them.

For other countries outside China, the researchers and firms can use these not extended Chinese patents as a good source of information and ideas which can be readily used. Nevertheless, the great effort made by China in the domain of the intellectual property is the evidence that China is leaving the copying mode or incremental innovation, to move to a true inventive mode (XIE et al., 2012), and then as people say go from "made in China" to the "made by China". It is clear that the work on the strategic dependence must be completed by other analysis dealing with strategic area of development, for example, the biofuel, the biodiesel, and the nanotubes. This work is underway and the first result confirm globally the conclusion of the above research.

\section{References}

Dou, H. (2012). Intelligence organisationnelle et des institutions. Veille Magazine, 131, 21-23.

Dou, H., Dou, J. M. Jr., \& Getachew, M. A. (2011). Automatic patent analysis-Technological strategic dependence. Beijing: ICTCI.

Dou, H., Leveillé, V., Manullang, S. D., \& Dou, J. M. Jr. (2005). Patent analysis for competitive technical intelligence and innovative thinking. Data Science Journal (DSJ), 4, 209-236.

IPC. (2013). Cooperative patent classification, espacenet. Retrieved from http://worldwide.espacenet.com/eclasrch?classification=ecla\&locale=en_EP\&ECLA=C09D5

Leydesdorff, L., \& Etzkowitz, H. (1998). The triple helix as a model for innovation studies. Science é Public Policy, 25(3), $195-203$. Matheo Software. (2013). Matheo patent Xe disponible. Retrieved from http://www.matheo-software.com

OECD. (2005). Main science and technology indicators. Paris, France: OECD Publishing.

PEN. (2012). Pan European networks science \& technology. Retrieved from http://www.paneuropeannetworks.com/sector/science-and-technology12.html

Tribune (La). (2010). Comment la Chine va devenir la championne du monde des brevets. Retrieved from http://www.latribune.fr/actualites/economie/international/20101012trib000559284/comment-la-chine-va-devenir-la-champio nne-du-monde-des-brevets-.html

WIPO. (2012). SME resources. Retrieved from http://www.wipo.int/sme/en/

XIE, X. Z., WANG, Q., \& Chen, A. Q. (2012). Analysis of competition in Chinese automobile industry based on an opinion and sentiment mining system. Journal of Intelligence Studies in Business JISIB, 2(1), 41-50. 